\title{
Towards a Naturalistic Conceptualisation of Technology Integration in Classroom Practice: the example of school mathematics
}

\section{Kenneth Ruthven}

\section{(2) OpenEdition}

\section{Journals}

Electronic version

URL: http://journals.openedition.org/educationdidactique/434

DOI: 10.4000/educationdidactique.434

ISBN: 978-2-7535-1620-5

ISSN: $2111-4838$

Publisher

Presses universitaires de Rennes

\section{Printed version}

Date of publication: 1 March 2009

Number of pages: 137-159

ISBN: 978-2-7535-0872-9

ISSN: 1956-3485

\section{Electronic reference}

Kenneth Ruthven, « Towards a Naturalistic Conceptualisation of Technology Integration in Classroom Practice: the example of school mathematics », Éducation et didactique [Online], 3-1 | mars 2009, Online since 01 March 2011, connection on 08 December 2020. URL : http://journals.openedition.org/ educationdidactique/434 ; DOI : https://doi.org/10.4000/educationdidactique.434 


\title{
TOWARDS A NATURALISTIC CONCEPTUALISATION OF TECHNOLOGY INTEGRATION IN CLASSROOM PRACTICE : THE EXAMPLE OF SCHOOL MATHEMATICS
}

\author{
Kenneth Ruthven, University of Cambridge
}

\begin{abstract}
Understanding the challenges of incorporating new technologies into classroom practice calls for the development of naturalistic perspectives that situate their adoption and use within the everyday work of teaching. In this light, recent British and French studies have developed and validated a model of secondary mathematics teachers' ideals for classroom use of computer-based tools and resources, and identified the crucial role of craft knowledge in realising these ideals in practice. From consideration of a wider literature base, this paper develops a conceptual framework that identifies key structuring features of classroom practice, showing how they relate to technology integration: working environment, resource system, activity format, curriculum script, and time economy. To illustrate a holistic application of this conceptual framework, it is used to analyse the practitioner thinking and professional learning surrounding an investigative lesson incorporating use of dynamic geometry. This demonstrates how the framework illuminates the professional adaptation on which technology integration into classroom practice depends
\end{abstract}

Key-words: classroom teaching; craft knowledge; instructional practices; mathematics education; practitioner thinking; professional adaptation; teacher learning; teaching resources; technology integration

Kenneth Ruthven

\section{Towards naturalistic study of technology integration}

This paper focuses on some crucial but largely overlooked facets of the incorporation of new technologies into classroom practice. Drawing on earlier research into structuring features of classroom practice and more recent studies of technology integration, it develops a conceptual framework intended to make these facets visible and analysable. Recognition of these facets helps to explain the now all too apparent gap between ambitious aspirations for new technologies in school and actual achievement. Despite the way in which "research in learning with technological tools has been showing much promise", it remains the case that "actual use of these tools in real school environments is still very thin despite the abundance of governmental funding", and that this situation calls for "deeper understanding of how the potential suggested by research... can be grounded... in classroom practices with respect to systemic schooling" (Kynigos, Bardini, Barzel \& Maschietto, 2007, p. 1332).

This is not a new phenomenon. Reviewing the educational reception of wave upon wave of new technologies over the last century, Cuban (1986, 1993, 2001) suggests that a recurrent pattern of response can be found: a cycle in which initial exhilaration, then scientific credibility, give way to practical disappointment, and consequent recrimination. He concludes that while new technologies have broadened teachers' instructional repertoires to a degree, they remain relatively marginal to classroom practice, and are rarely used for more than a fraction of the school week. Indeed, for scholars of school reform, this forms part of a much wider pattern of largely unsuccessful attempts to change the structures of curriculum, pedagogy and assessment at the heart of schooling. Cuban (1986, pp. 81-82) argues that the characteristic features of "teacher-centred instruction" evolved in the face of "the implacable reality that policy makers institutionalised over a century ago". In this reality, "a teacher is required to face thirty or more students in a classroom for a set period of time, maintain order, and inspire the class to learn content and skills mandated by the community". Cuban refers to this as "the DNA of classroom life". It forms part of what Tyack and Tobin (1994, p. 454) term "the grammar of schooling". These evocative metaphors seek to convey the way in which schooling has a core structure encoded in the three Cs of classroom, curriculum and certification. Such a system, suggests Cuban (2001, p. 830), is capable of no more than a slow "incrementalism [which] will only marginally reshape the deeply entrenched structures". 
Critiquing this line of argument, Papert (1997) objects that it simply describes the "defense mechanisms" of schooling which serve to "frustrate reform" (p. 418). These mechanisms, Papert argues, "are concomitants rather than causes of [its] stability" (p. 419). What is agreed on both sides, however, is that while innovations set out to change schooling, a reciprocal process unfolds in which schooling changes innovations. This has led Papert towards a "shift from a stance of reform to a stance of evolution" (p. 418). He argues that "the most insightful... teachers working in conventional schools understand what they are doing today... [as] not being the ideal they wish for". He suggests that "as ideas multiply and as the ubiquitous computer presence solidifies, the prospects of deep change become more real" (p. 423). In particular, he sees the day-to-day classroom work with computers of these teachers as the seeds from which such change will grow.

Indeed, contemporary theories of educational change, just like those of technological innovation, acknowledge how these processes are shaped by the sense-making of the agents involved (Spillane, Reiser \& Reimer, 2002). Accordingly, conceptualisations of how teachers use curriculum materials have advanced beyond rather limited views of teachers as simply following or subverting such materials, to more sophisticated perspectives encompassing teacher interpretation of, and participation with, curriculum materials (Remillard, 2005). Teachers necessarily incorporate the use of such materials into wider systems of classroom practice, so that the designs of curriculum developers turn out, in the words of Ball and Cohen (1996, p. 6), "to be ingredients in - not determinants of - the actual curriculum". Hence, examining teacher response to new technologies, Kerr (1991; p. 121) has argued: "If technology is to find a place in classroom practice it must be examined in the context of classroom life as teachers live it".

This paper follows that injunction towards a more naturalistic perspective on technology integration. In particular, it seeks to make visible the "practical theory' (Deaney, Ruthven \& Hennessy, 2006; Kroath, 1989) and 'craft knowledge' (Brown \& McIntyre, 1993; Ruthven, 2002a) that frame teachers' thoughts and actions. These terms draw attention to important characteristics of teachers' professional knowledge and thinking: strongly moulded by, and closely fitted to, the practice of teaching and its setting; largely developed through (often unconscious, sometimes reflective) adaptation in response to experience. While recent work within this tradition has tended to celebrate idiosyncratic aspects of such knowledge and thinking, and emphasised their embedding in personal narrative (Kennedy, 1999; Munby, Russell $\&$ Martin, 2001), the research to be presented here highlights commonalities, first in the collective representations underpinning such knowledge and thinking, and then in the structuring features which shape them.

The particular focus of this paper will be on mathematics teaching. That reflects not only the audience for which the paper was originally written ${ }^{1}$, but the substantial attention which mathematics has received in the research literatures both on classroom practice and on technology integration. However, from research covering several curriculum areas in which I have recently been involved (such as Deaney et al., 2006; Hennessy, Deaney \& Ruthven, 2005; Hennessy, Ruthven \& Brindley, 2005; Ruthven, Hennessy \& Brindley, 2004; Ruthven, Hennessy \& Deaney, 2005b), my sense is that the broad thrust of the argument to be developed here goes beyond this specific subject. Rather, mathematics is a particularly telling example because it was one of the first areas of the curriculum where interest developed in the potential of computing. Consequently, it is one where there has been an unusually longstanding and substantial investment in providing computer tools, developing educational resources, and encouraging teachers to use them. Nevertheless, as recent TIMSS studies evidence (Mullis et al., 2004; Ruthven, in press), there is still little pervasive use of computers in school mathematics.

\section{A practitioner model of computer use in school mathematics}

To develop a better understanding of the appropriation of new technologies by classroom teachers, we undertook a study in Cambridge during the year 2000. This study investigated mathematics teachers' ideas about their own experience of successful classroom use of computer-based tools and resources (Ruthven \& Hennessy, 2002). Teacher accounts were elicited through focus group interviews with subject 
departments in secondary schools. These interviews were then analysed, qualitatively and quantitatively, so as to map central themes and primary relationships between them. Through a recursive process of constant comparison, themes were identified within the interview transcripts and related material coded. The degree to which pairs of themes occurred within the same transcript segments was assessed by computing a coefficient of association. The strongest associations were included as linkages between themes in the model shown in Figure 1. This diagram summarises and organises the key ideas of the practical theory implicit in mathematics teachers' accounts of successful practice ${ }^{2}$.

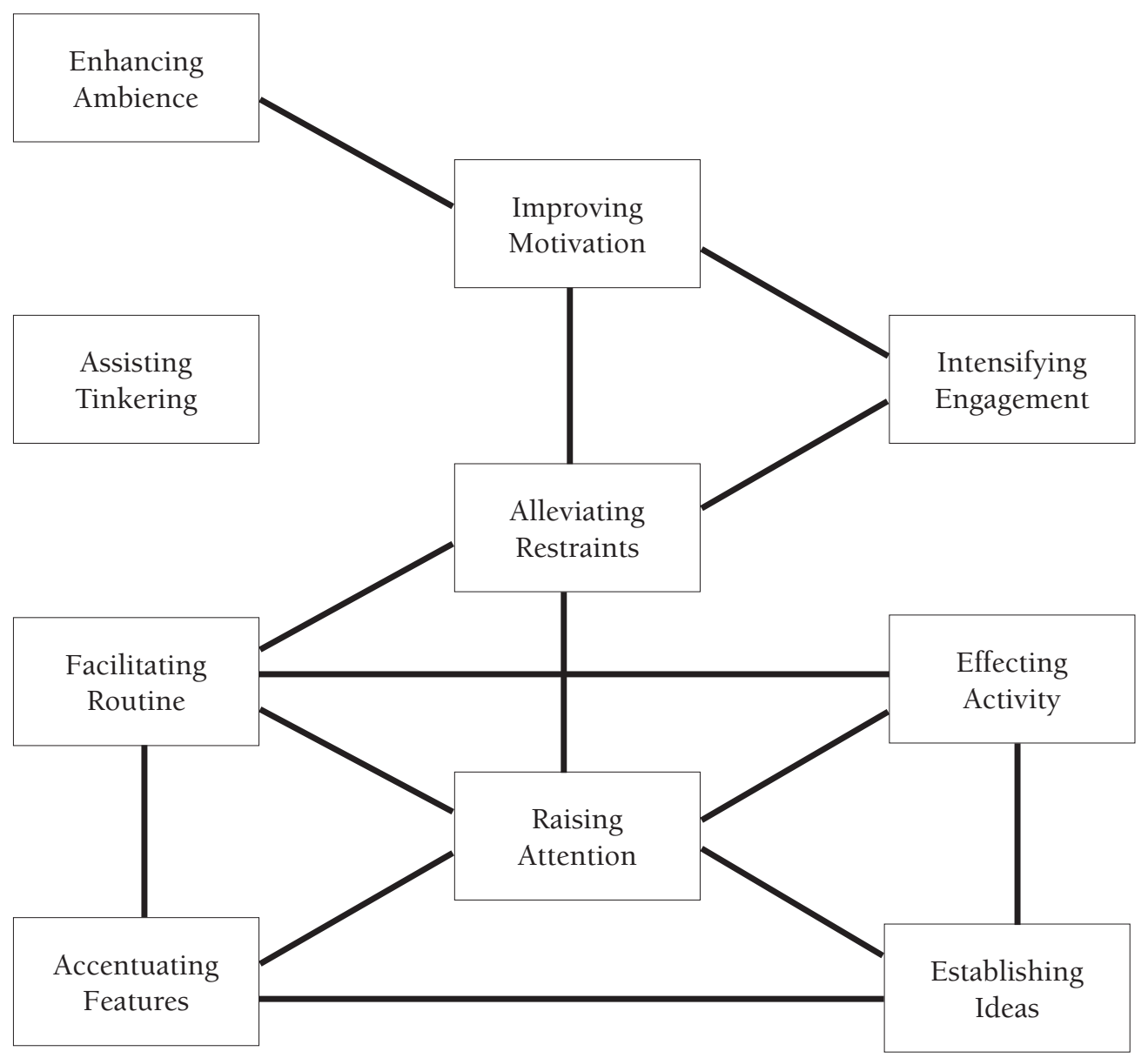

Figure 1: A practitioner model of the use of computer-based tools and resources in secondary-school mathematics (Ruthven $E$ Hennessy, 2002)

At the left of the diagram are those themes related to direct affordances of computer-based tools and resources. Such tools and resources can serve as means of: Enhancing ambience through varying and enlivening the form and feel of classroom activity; Assisting tinkering through aiding correction of errors and experimentation with possibilities; Facilitating routine by enabling subordinate tasks to be carried out easily, rapidly and reliably; and Accentuating features by providing vivid images and striking effects to highlight properties and relations. At the right of the diagram are those themes more directly related to major teaching goals. Intensifying engagement relates to securing the participation of students in classroom activity; Effecting activity relates to maintaining the pace of lessons and productivity 
of students; Establishing ideas relates to supporting progression in student understanding and capability. In an intermediate position lie the key bridging themes: Improving motivation by generating student enjoyment and interest, and building student confidence; Alleviating restraints by making tasks less laborious for students, and reducing their sensitivity over mistakes being exposed; and Raising attention through creating conditions which help students to focus on overarching issues.

This model should not be read deterministically as implying that exploitation of the technological affordances on the left leads inevitably to achievement of the teaching aspirations on the right. Rather, each construct represents a desirable state of affairs which teachers seek to bring about in the classroom, and to which they see the use of technology as capable of contributing. Of course, not all the components of the model were present in every example of successful practice, and some assumed more prominence than others. However, across the departmental interviews as a whole, all of the themes were invoked in the great majority of schools, indicating that they enjoy a wide currency. On the basis of this single study, the model had to be regarded as a tentative one. It was based only on teachers' decontextualised accounts of what they saw as successful practice, not on more strongly contextualised accounts of specific instances of practice, supported by examination of actual classroom events. Nevertheless, the model triangulated well against published case studies of technology use in ordinary classrooms, reported from the United States, suggesting that it might be more widely transferable.

Subsequent studies have offered support for the model as an expression of teachers' ideals. One such study was carried out by the Cambridge team during 2004 , in a fresh group of schools which were professionally well regarded for their use of information and communication technology (ICT) in mathematics. Here, the emphasis of teachers' accounts of successful classroom use of dynamic geometry was on the themes from the lower part of the model (Ruthven, Hennessy \& Deaney, 2005a; Ruthven, Hennessy \& Deaney, 2008). In terms of Facilitating routine and Effecting activity, the software was valued for making student work with figures easier, faster and more accurate; and consequently, in terms of Raising atten- tion, for removing drawing demands which distract students from the key point of a lesson. In terms of Accentuating features and Establishing ideas, dragging a dynamic figure enabled students to "see it changing" and "see what happens", so that properties "become obvious" and students "see them immediately", promoting conviction, understanding and remembering.

This model was taken up in an independent study, carried out by members of the DIDIREM team in Paris during 2003. This study examined the practice of experienced teachers who were longstanding classroom users of computer-based tools and resources, and involved in professional development networks (Caliskan-Dedeoglu, 2006; Lagrange \& Caliskan-Dedeoglu, in press). It found that the model provided a useful template to describe teachers' pedagogical rationales for the classroom use of dynamic geometry. However, when teachers were followed into the classroom it became clear that these rationales sometimes proved difficult to realise in the lessons themselves. Teachers could be overly optimistic about the ease with which students would be able to use the software. Far from Facilitating routine and Alleviating restraints, computer mediation might actually impede student actions, with the teacher trying to retrieve the situation by acting primarily as a technical assistant. Equally, students could encounter difficulties in relating the figure on the computer screen to its paper-and-pencil counterpart. Rather than Accentuating features, computer mediation might call them into question.

This serves to emphasise the point made earlier that while the model identifies the types of "normal desirable state' (Brown \& McIntyre, 1993) which teachers associate with successful technology use, actually achieving such success depends on establishing classroom conditions and pursuing teaching actions which create and maintain these states. In particular, this calls for a corresponding development of teachers' craft knowledge. Certainly in the later Cambridge study, there was evidence of such development having taken place (Ruthven et al., 2005a). Teachers were found to have developed strategies to avoid or overcome potential obstacles. For example, the potential for student difficulties in using the software was often reduced by providing them with a prepared figure or by leading them through the construction process. Where students 
were expected to make fuller use of the software, we observed one teacher establishing a 'tidying' routine in which students eliminated the spurious points and lines that they often created onscreen as a result of their difficulties in physically manipulating the pointer. Likewise, we observed one teacher incorporate a lesson segment which served to bridge between a dynamic geometry figure and what might otherwise have appeared to students as a quite dissimilar pencil and paper counterpart. What these two studies emphasise, then, is that the model represents a guiding ideal for teachers. Realising this ideal depends on teachers developing a craft knowledge to support their desired classroom use of new technologies.

\section{Structuring features of classroom practice}

The complexity and significance of craft knowledge in teaching is often overlooked (Brown \& McIntyre, 1993; Leinhardt, 1988). In particular, much proposed innovation entails modification of this largely reflex system of powerful schemes, routines and heuristics that teachers bring to their classroom work, often tailored to particular circumstances. In this light, the following discussion will examine five key structuring features of classroom practice, showing how they relate to the incorporation of computer use: working environment, resource system, activity format, curriculum script, and time economy.

\section{Working environment}

The use of computer-based tools and resources in teaching often involves changes in the working environment of lessons: change of room location and physical layout, change in class organisation and classroom procedures (Jenson \& Rose, 2006).

In many schools, lessons have to be relocated from the regular classroom to a computer laboratory for computers to be available in sufficient numbers for students to work with them. Such use has to be anticipated by the teacher, and it prevents more spontaneous and flexible use of the technology (Bauer \& Kenton, 2005; Monaghan, 2004; Ruthven \& Hennessy, 2002). It also entails disruption to normal working practices and makes additional organisational demands on the teacher (Jenson \& Rose, 2006; Ruthven et al., 2005b). Well-established routines which help lessons to start, proceed and close in a timely and purposeful manner in the regular classroom (Leinhardt, Weidman \& Hammond, 1987) have to be adapted to the computer laboratory. Simply organising students to arrive there for the lesson rather than their regular classroom, or moving them as a class between rooms during the lesson, introduces extra demands (Bauer \& Kenton, 2005; Ruthven et al., 2005b). Particularly when done on only an occasional basis, teacher and students must also adapt to an unfamiliar working environment. They are likely to be less familiar with the facilities of the computer laboratory, and less likely to have customised them. Often, too, the number of workstations is smaller than the number of students in the class. Typically this leads to students being paired at a workstation. Alternatively, the class may be split in two, alternating between working at a computer and away from it. Neither of these is a common form of organisation in mathematics lessons in ordinary classrooms, and the second calls for careful management of transition procedures, and simultaneous supervision of two different activities.

As the provision of sets of handheld devices or laptop computers for use in ordinary classrooms becomes more common in schools, these organisational issues shift rather than disappear. If students are given responsibility for a personal machine, difficulties emerge which have parallels with more traditional student tools and resources: for example, students may forget to recharge their machines or neglect to bring them to school (Zucker \& McGhee, 2005), particularly if their use within lessons is irregular. Alternatively, if a class set of machines is used, these typically have to be set up at the start of each lesson and put away at the close. Often, too, there is poor provision for students' work to be saved or printed, particularly in a form which can be integrated with their written work, and used in other lessons and at home. Finally, with a computer at their fingertips, students have many opportunities for distraction. Teachers report having to develop classroom layouts assisting them to monitor students' computer screens, as well as classroom routines to forestall distraction, such as having students push down the screens of their laptops during whole-class lesson segments (Zucker \& McGhee, 2005). 
While the modifications in working environment discussed here may contribute - in the terms of the earlier practitioner model - to Enhancing ambience, they introduce new demands on teachers and students. Individually, each of these disruptions or additions to normal practice may amount to little. Cumulatively, however, they increase complexity and uncertainty, and call for significant adaptation of classroom routines. Consequently, in many educational systems there has been a trend towards provision of computer (or calculator) projection facilities or interactive whiteboards in ordinary classrooms. To the extent that such facilities can be treated as a convenient enhancement of a range of earlier display and projection devices, and allow a single classroom computer to be managed by teachers on behalf of the whole class, they involve relatively little modification to working environment (Jewitt, Moss \& Cardini, 2007; Miller \& Glover, 2006).

\section{Resource system}

New technologies have broadened the types of resource ${ }^{3}$ available to support school mathematics. Educational suppliers now market textbook schemes alongside revision courseware, concrete apparatus alongside computer microworlds, manual instruments alongside digital tools. As many teachers realise, however, there is a great difference between a collection of resources and a coherent system. The concept of 'resource system' focuses, then, on the combined operation of the mathematical tools and curriculum materials in classroom use, particularly on their compatibility and coherence of use, and on factors influencing this. The use of system reflects the challenge which teachers face in combining and adapting what otherwise would be merely a collection of resources to function in a co-ordinated way aligned with their curricular and pedagogical goals (Amarel, 1983).

Studies of the classroom use of computer-assisted instructional packages have attributed take-up of particular materials to their clear alignment with the regular curriculum and their flexibility of usage (Morgan, 1990). Frequently, however, evaluations of instructional packages have reported problems of mismatch with the regular curriculum (Amarel, 1983; Warschauer \& Grimes, 2005; Wood, 1998). Equally, more general evaluations of technology integration have pointed to a paucity of curriculum-appropriate materials (Conlon \& Simpson, 2003; Zucker \& McGhee, 2005). Teachers report that they would be much more likely to use technology if ready-to-use resources were readily available to them and clearly mapped to their scheme of work (Crisan, Lerman \& Winbourne, 2007). Such barriers are exacerbated by a limited scope for teacher adaptation and reorganisation of much CAI material. Such experiences have encouraged developers to offer greater flexibility to teachers. For example, recent studies have examined use of a bank of e-exercises on which teachers can draw to design on-line worksheets for their students (Bueno-Ravel \& Gueudet, 2007; Abboud-Blanchard, Cazes \& Vandebrouck, 2007). These studies show that teachers need to acquire the same depth of knowledge of the e-exercises as of textbook material in order to make effective use of them and to integrate them successfully with other classroom activity.

The printed textbook still remains at the heart of the resource system for studying mathematics in most classrooms. Textbooks are valued for establishing a complete, consistent and coherent framework, within which material is introduced in an organised and controlled way, appropriate to the intended audience. Indeed, one common use of interactive whiteboards in classrooms is to project and annotate textbook pages or similar presentations (Miller \& Glover, 2006). More broadly, educational publishers are seeking increasingly to bundle digital materials with printed textbooks, often in the form of presentations and exercises linked to each section of the text, or applets providing demonstrations and interactivities. Such materials are attractive to many teachers because they promise a relatively straightforward and immediately productive integration of old and new technologies.

Textbook treatments of mathematical topics necessarily make assumptions about what kinds of tools will be available in the classroom. Historically, expectations have been very modest. However, textbooks increasingly assume that some kind of calculator will be available to students. Well designed textbooks normally include sections which develop the techniques required in using calculators and establish some form of mathematical framing for them. However, it is rare to find textbooks taking account 
of other digital mathematical tools. Here, textbook developers face the same problems as classroom teachers. In the face of a proliferation of available tools, which should be prioritised? And given the currently fragmentary knowledge about bringing these tools to bear on curricular topics, how can a coherent use and development be achieved? Such issues are exacerbated when tools are imported into education from the commercial and technical world. Often, their intended functions, operating procedures, and representational conventions are not well matched to the needs of the school curriculum (as will be explored further in a later section).

\section{Activity format}

Classroom activity is organised around formats for action and interaction which frame the contributions of teacher and students to particular lesson segments (Burns \& Anderson, 1987; Burns \& Lash, 1986). The crafting of lessons around familiar activity formats and their supporting classroom routines helps to make them flow smoothly in a focused, predictable and fluid way (Leinhardt, Weidman \& Hammond, 1987). Indeed, this leads to the creation of prototypical activity structures or cycles for particular styles of lesson.

Monaghan (2004) has given particular attention to activity structure in computer-based lessons. His Leeds study involved a number of secondary teachers who had made a commitment to move - during one school year - from making little use of ICT in their mathematics classes to making significant use. For each participating teacher, a 'non-technology' lesson was observed at the start of the project, and further 'technology' lessons over the course of the year. Monaghan found that 'technology' lessons tended to have a quite different activity structure from 'non-technology'. In all the observed 'non-technology' lessons, teacherled exposition including the working-through of examples was followed by student work on related textbook exercises. Of the observed 'technology' lessons, only those which took place in the regular classroom using graphic calculators displayed this type of structure. Most of the 'technology' lessons focused on more 'open' tasks, often in the form of investigations. These featured an activity structure consisting typically of a short introduction to the task by the teacher, followed by student work at computers over most of the session. Both types of 'technology' lesson observed by Monaghan appear, then, to have adapted an existing form of activity structure: less commonly that of the expositionand-practice lesson; more commonly that of the investigation lesson. While, in one sense, such use of technology is simply helping teachers to realise an established form of practice, what is significant is that it may be enabling them to do so more effectively and extensively. Monaghan reports that many Leeds teachers saw use of technology as particularly supportive of investigation lessons; likewise, Cambridge teachers suggested that, by helping to create classroom conditions in which investigations can be conducted more successfully, particularly with lower attaining students, technology makes this type of lesson a more viable option (Ruthven $\&$ Hennessy, 2002).

Other studies describe classroom uses of new technologies that involve more radical change in activity formats, and call for new classroom routines. For example, to provide an efficient mechanism through which the teacher can shape and regulate methods of tool use, Trouche (2005) introduces the role of 'sherpa student', taken on by a different student in each lesson. The sherpa student becomes responsible for managing the calculator or computer being publicly projected during whole-class activity; by guiding the actions of this student, or by opening them up for comment and discussion, the teacher can manage the collective development of techniques for using the tool. Likewise, Trouche proposes new activity formats for student groupwork. In the format of 'mirror observation', two pairs of students alternate roles, each pair taking their turn in making an analytic record of the problem solving activity of the other pair, providing a basis for subsequent reflective discussion. In the format of 'practical work', a similar basis for reflective review is provided by a 'practical notebook' in which a pair of students records each stage of their work on a research task, explaining and justifying their decisions about what to do and what to record. What needs to be noted is that each of these modifications of an established activity format calls for the establishment of new classroom norms for participation, and of classroom routines to support smooth functioning. 


\section{Curriculum script}

In planning to teach a topic, and in conducting lessons on it, teachers draw on a matrix of professional knowledge. This knowledge has been gained in the course of their own experience of learning and teaching the topic, or gleaned from available curriculum materials. At the core of this matrix is a loosely ordered model of relevant goals and actions which serves to guide their teaching of the topic. This forms what has been termed a 'curriculum script' - where 'script' is used in the psychological sense of a form of event-structured cognitive organisation, which includes variant expectancies of a situation and alternative courses of action (Leinhardt, Putnam, Stein \& Baxter, 1991). This script interweaves ideas to be developed, tasks to be undertaken, representations to be employed, and difficulties to be anticipated (as already touched on in earlier sections of this paper $)^{4}$.

Our Cambridge studies have focused on what teachers nominated as examples of successful practice. In their accounts, teachers frequently appear to be viewing the use of new technologies in terms of the adaptation and extension of established curriculum scripts. For example, they talk about the new technology as a means of improving existing practices, suggesting that it serves as a more convenient and efficient tool, or provides a more vivid and dynamic presentation. Nevertheless, it is easy to underestimate the host of small but nuanced refinements which existing curriculum scripts require in order even to assimilate a new technology, let alone adapt in the light of fresh insights gained from working with it (as will be demonstrated in the case study presented in the next section).

When teachers participate in development projects, they experience greater pressure (often self-administered) to go beyond the familiar in using technology more innovatively. In the Leeds project, for example, teachers seem to have put themselves in a position where, as one expressed it, "you're doing ICT and it's the first time you've done a topic like that" (Monaghan, 2004, p. 337). It appears that teachers found little to draw on, either in their existing curriculum scripts or the teaching resources available to them, to help them devise and conduct 'technology' lessons on an investigative model. Consequently, they were obliged to plan such lessons at length and in detail, and then found themselves teaching rather inflexibly. The extent and complexity of such adoption is still greater when, as noted earlier, 'imported' technologies need to be aligned with the school curriculum. Monaghan compares, for example, the relative ease with which new lessons could be devised around the use of graphware specifically devised for educational use, with the much greater demands of appropriating 'imported' computer algebra systems to curricular purposes.

For that reason, the challenges identified by projects seeking to make curricular use of 'imported' technologies chart the extremes of adaptation, particularly in an educational culture which places emphasis on the rigorous articulation of mathematical ideas and arguments. This explains why such complexities have emerged particularly strongly in French research on computer algebra systems (Ruthven, 2002b; Fey, 2006). As Artigue (2002) points out, in such a culture the expectation is that a teacher's curriculum script for a mathematical topic will identify those techniques to be recognised as standard (under the influence, of course, of wider institutional norms), and provide for these to be acknowledged, justified and rehearsed (often supported, of course, by relevant curricular materials). The studies that Artigue summarises point to the degree of decalage between - on the one hand - a relatively compact system of classical techniques already endowed with a strong institutional framing and - on the other - an extraordinary diversity of computer techniques often exploiting distinctive characteristics of the digital medium which have no classical counterparts. Under these circumstances, adapting and extending an existing curriculum script so as to interleave use of the computer system presented very considerable challenges. Doing so was found to depend, amongst other things, on developing a coordinated understanding of both the knowledgebuilding and task-effecting value of components of the classical and computer systems, and establishing a coherent teaching sequence for developing student knowledge and skill within the two systems.

\section{Time economy}

Time is a currency in which teachers calculate many of their decisions. It features strongly in 
the ideals of the practitioner model of successful classroom computer use where the processes of Facilitating routine and Raising attention serve in Effecting activity in terms both of the pace of lessons and the productivity of students. However many studies report teachers' very real concerns about the time costs of "squeez[ing] technology into the curriculum when there is so much, skill wise, to teach" (Bauer \& Kenton, 2005, p. 534; Crisan, Lerman \& Winbourne, 2007; Smerdon et al., 2000). And there is a cost associated with innovation itself. While teachers are developing the requisite craft knowledge, lessons require more detailed preparation and are often conducted less efficiently and flexibly (Assude, 2005; Monaghan, 2004).

In her study of dynamic geometry integration in the primary school classroom, Assude (2005) highlighted how teachers seek to improve the 'rate' at which the physical time available for classroom activity is converted into a 'didactic time' measured in terms of the advance of knowledge. Her study shows how important the fine-tuning of resource systems, activity structures and curriculum scripts is in improving this rate of didactic 'return' on time 'investment'. One aspect of this is the way in which old technologies typically remain in use alongside new, not just because they have a symbolic value, but because they make an epistemic knowledge-building contribution as much as a pragmatic task-effecting one (Artigue, 2002). This 'double instrumentation' means that new technologies often give rise to additional costs rather than to cost substitutions with respect to time. A critical issue is what teachers perceive as the return in terms of recognised mathematical learning from students using new tools. Teachers are cautious about new tools which require substantial investment, and alert for modes of use which reduce such investment and increase rates of return (Ruthven et al., 2008).

These concerns are further evidenced in the trend to equip classrooms with interactive whiteboards, popularised as a technology for increasing the pace and efficiency of lesson delivery, as well as harnessing multimodal resources and enhancing classroom interaction (Jewitt et al., 2007). Evaluating the developing use of interactive whiteboards in secondary mathematics classrooms, Miller \& Glover (2006) found that teachers progressed from initial teaching approaches in which the board was used only as a visual support for the lesson, to approaches where it was used more deliberately to demonstrate concepts and stimulate responses from pupils. Over time, there was a marked shift away from pupils copying down material from the board towards use "at a lively pace to support stimulating lessons which minimise pupil behaviour problems" (p. 4). However, in terms of the type of curricular resource used with the board, there was little progression beyond textbook type sources and prepared presentation files, with generic mathematics software such as spreadsheet, graphing and geometry programs rejected by teachers as overcomplex or used by them only in limited ways.

\section{An investigative lesson with dynamic geometry}

The conceptual framework sketched in the last section will now be used to analyse the practitioner thinking and professional learning surrounding a lesson incorporating the use of dynamic geometry. This lesson was one of four cases examined in the Cambridge study of classroom practice of dynamic geometry use (Ruthven et al., 2008). Because the teacher was unusually expansive, this case has provided a convenient interim means to explore a more holistic application of the conceptual framework to a concrete example of teaching.

\section{Orientation to the lesson}

The teacher explained, when nominating the lesson, that it had been developed in response to improved technology provision in the mathematics department, notably the introduction of interactive whiteboards in ordinary classrooms:

We'd got the interactive whiteboards fairly new, and I wanted to explore some geometry... We'd done some very rough work on constructions with compasses and bisecting triangles and then I extended that to Geometer's Sketchpad... on the interactive whiteboard using it in front of the class.

He reported that the lesson (with a class in the early stages of secondary education) had started 
with him constructing a triangle, and then the perpendicular bisectors ${ }^{5}$ of its edges. The focus of the investigation which ensued had been on the idea that this construction might identify the 'centre' of a triangle:
And we drew a triangle and bisected the sides of a triangle and they noted that they all met at a point. And then I said: "Well let's have a look, is that the centre of a triangle?" And we moved it around and it wasn't the centre of the triangle, sometimes it was inside the triangle and sometimes outside.

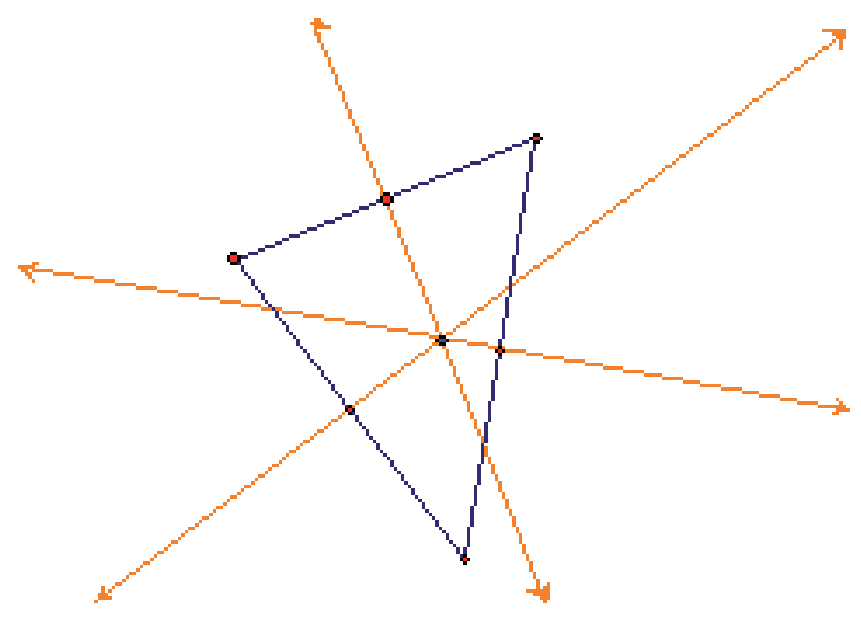

Figure 2: The basic dynamic figure employed in the investigative lesson (Ruthven et al., 2008)

According to the teacher, one particularly successful aspect of the lesson had been the extent to which students actively participated in the investigation:

And they were all exploring; sometimes they were coming up and actually sort of playing with the board themselves... I was really pleased because lots of people were taking part and people wanted to come and have a go at the constructions.

Indeed, because of the interest and engagement shown by students, the teacher had decided to extend the lesson into a second session, held in a computer room to allow students to work individually at a computer:

And it was clear they all wanted to have a go so we went into the computer room for the next lesson so they could just continue it individually on a computer... I was expecting them all to arrive in the computer room and say: "How do you do this? What do I have to do again?"... But virtually everyone... could get just straight down and do it. I was really surprised. And the constructions, remembering all the constructions as well.

For the teacher, then, this recall by students of ideas from the earlier session was another striking aspect of the lesson's success.

In terms of the specific contribution of dynamic geometry to this success, the teacher noted how the software supported exploration of different cases, and overcame the practical difficulties which students encountered in using classical tools to attempt such an investigation by hand:

You can move it around and see that it's always the case and not just that one off example. But I also think they get bogged down with the technicalities of drawing the things and getting their compasses right, and [dealing with] their pencils broken.

But the teacher saw the contribution of the software as going beyond ease and accuracy; using 
it required properties to be formulated precisely in geometrical terms:

And it's the precision of realising that the compass construction... is about the definition of what the perpendicular bisector is... And Geometer's Sketchpad forces you to use the geometry and know the actual properties that you can explore.

These, then, were the terms in which the original lesson was nominated as an example of successful practice. We followed up this nomination by studying a later lesson along similar lines, gathering evidence through classroom observations and teacher interviews. The observed lesson was conducted over two 45-minute sessions on consecutive days with a Year 7 class of students (aged 11-12) in their first year of secondary education.

\section{Working environment}

Each session of the observed lesson started in the normal classroom and then moved to a nearby computer suite where it was possible for students to work individually at a machine. This movement between rooms allowed the teacher to follow an activity cycle in which working environment was shifted to match changing activity format.

Even though the computer suite was, like the teacher's own classroom, equipped with a projectable computer, starting sessions in the classroom was expedient for several reasons. Doing so avoided disruption to the established routines underpinning the smooth launch of lessons. Students could be expected to arrive at the normal classroom on time and prepare themselves for work as usual. Moreover, the classroom provided an environment more conducive to sustaining effective communication during whole-class activity and to maintaining the attention of students. Whereas in the computer suite each student was seated behind a sizeable monitor, blocking lines of sight and placing diversion at students' fingertips, in the classroom the teacher could introduce the lesson "without the distraction of computers in front of each of them".

It was only recently that the classroom had been refurbished and equipped, and a neighbouring computer suite established for the exclusive use of the mathematics department. The teacher contrasted this new arrangement favourably in terms of the easier and more regular access to technology that it afforded, and the consequent increase in the fluency of students' use. New routines were being established for students opening a workstation, logging on to the school network, using shortcuts to access resources, and maximising the document window. Likewise, routines were being developed for closing computer sessions. Towards the end of each session, the teacher prompted students to plan to save their files and print out their work, advising them that he'd "rather have a small amount that you understand well than loads and loads of pages printed out that you haven't even read". He asked students to avoid rushing to print their work at the end of the lesson, and explained how they could adjust their output to try to fit it onto a single page; he reminded them to give their file a name that indicated its contents, and to put their name on their document to make it easy to identify amongst all the output from the single shared printer.

\section{Resource system}

The department had its own scheme of work, with teachers encouraged to explore new possibilities and report to colleagues. This meant that they were accustomed to integrating material from different sources into a common scheme of work. However, so wide was the range of computer-based resources currently being trialled that our informant (who was head of department) expressed concern about incorporating them effectively in departmental schemes, and about the demands of familiarising staff and students with such a variety of tools.

In terms of coordinating use of old and new technologies, work with dynamic geometry was seen as complementing established work on construction by hand, by strengthening attention to the related geometric properties:

I thought of Geometer's Sketchpad [because] I wanted to balance the being able to actually draw [a figure] with pencil and compasses and straight edges, with also seeing the geometrical facts about it as well. And sometimes [students] don't draw it accurately enough 
to get things like that all the [perpendicular bisectors] meet at the orthocentre ${ }^{5}$ of the circle.

Nevertheless, the teacher felt that old and new tools lacked congruence, because certain manual techniques appeared to lack computer counterparts. Accordingly, old and new were seen as involving different methods and having distinct functions:

When you do compasses, you use circles and arcs, and you keep your compasses the same. And I say to them: "Never move your compasses once you've started drawing." ... Well Geometer's Sketchpad doesn't use that notion at all... So it's a different method. Whether they then can translate that into compasses and pencil construction, I don't think there's a great deal of connection. I don't think it's a way of teaching constructions, it's a way of exploring the geometry.

Equally, some features of computer tools were not wholly welcome. For example, students could be deflected from the mathematical focus of a task by overconcern with presentation. During the lesson the teacher had tried out a new technique for managing this, by briefly projecting a prepared example to show students the kind of report that they were expected to produce, and illustrating appropriate use of colour coding:

They spend about three quarters of the lesson making the font look nice and making it all look pretty [but] getting away from the maths. There's a little potential for doing that, but I was very clear. I think it was good. I've never tried it before, but that showing at the end roughly what I wanted them to have would help. Because it showed that I did want them to think about the presentation, I did want them to slightly adjust the font and change the colours a little bit, to emphasise the maths, not to make it just look pretty.

Here, then, we see the development of sociomathematical norms (Yackel \& Cobb, 1996) for using new technologies, and classroom strategies for establishing and maintaining these norms.

\section{Activity format}

Each session of the observed lesson followed a similar activity cycle, starting with teacher-led activity in the normal classroom, followed by student activity at individual computers in the nearby computer suite, and with change of rooms during sessions serving to match working environment to activity format. Indeed, when the teacher had first nominated this lesson, he had remarked on how it combined a range of classroom activity formats to create a promising lesson structure:

There was a bit of whole class, a bit of individual work and some exploration, so it's a model that I'd like to pursue because it was the first time I'd done something that involved quite all those different aspects.

In discussing the observed lesson, however, the teacher highlighted one aspect of the model which had not functioned as well as he would have liked: the fostering of discussion during individual student activity. He identified a need for further consideration of the balance between opportunities for individual exploration and for productive discussion, through exploring having students work in pairs:

There was not as much discussion as I would have liked. I'm not sure really how to combine working with computers with discussing. You can put two or three [students] on a computer, which is what you might have done in the days when we didn't have enough computers, but that takes away the opportunity for everybody to explore things for themselves. Perhaps in other lessons... as I develop the use of the computer room I might decide... [to] work in pairs. That's something I'll have to explore.

At the same time, the teacher noted a number of ways in which the computer environment helped to support his own interactions with students within an activity format of individual working. Such opportunities arose from helping students to identify and resolve bugs in their dynamic geometry constructions:

[Named student] had a mid point of one line selected and the line of another, so he had a perpendicular line to another, and he didn't actually notice which is worrying... And that's what I was trying to do when I was going round to individuals. They were saying: "Oh, something's wrong." So I was: "Which line is perpendicular to that one?"

Equally, the teacher was developing ideas about the pedagogical affordances of text-boxes, realising 
that they created conditions under which students might be more willing to consider revising their written comments:

And also the fact that they had a text box and they had to write it, and they could change it and edit it. They could actually then think about what they were writing, how they describe, I could have those discussions. With handwritten, if someone writes a whole sentence next to a neat diagram, and you say: "Well actually, what about that word? Can you add this in?" You've just ruined their work. But with technology you can just change it, highlight it and add on an extra bit, and they don't mind. And that's quite nice... I hadn't really thought about that until today, to be honest.

This was helping him to achieve his goal of developing students' capacity to express themselves clearly in geometrical terms:

I was focusing on getting them to write a rule clearly. I mean there were a lot writing "They all meet" or even, someone said "They all have a centre."... So we were trying to discuss what "all" meant, and a girl at the back had "The perpendicular bisectors meet", but I think she'd heard me say that to someone else, and changed it herself. "Meet at a point": having that sort of sentence there.

\section{Curriculum script}

The observed lesson followed on from earlier ones in which the class had undertaken simple constructions with classical tools: in particular, using compasses to construct the perpendicular bisector of a line segment. Further evidence that the teacher's curriculum script for this topic originated prior to the availability of dynamic geometry was his reference to the practical difficulties which students encountered in working by hand to accurately construct the perpendicular bisectors of a triangle. His evolving script now included knowledge of how software operation might likewise derail students' attempts to construct perpendicular bisectors, but also of how such difficulties might be turned to advantage in reinforcing the mathematical focus of the task:

Understanding the idea of perpendicular bisector... you select the line and the [mid]point... There's a few people that missed that and drew random lines... And I think they just misunderstood, because one of the awkward things about it is the selection tool. If you select on something and then you select another thing, it adds to the selection, which is quite unusual for any Windows package... So you have to click away and de-select things, and that caused a bit of confusion, even though I had told them a lot. But... quite a few discussions I had with them emphasised which line is perpendicular to that edge... So sometimes the mistakes actually helped.

Equally, the teacher's curriculum script anticipated that students might not appreciate the geometrical significance of the concurrence of perpendicular bisectors, and incorporated strategies for addressing this:

They didn't spot that [the perpendicular bisectors] all met at a point as easily... I don't think anybody got that without some sort of prompting. It's not that they didn't notice it, but they didn't see it as a significant thing to look for... even though there were a few hints in the worksheet that that's what they were supposed to be looking at, because I thought that they might not spot it. So I was quite surprised... that they didn't seem to think that three lines all meeting at a point was particularly exceptional circumstances. I tried to get them to see that... three random lines, what was the chance of them all meeting at a point.

The line of argument alluded to here was one already applicable in a pencil and paper environment. Later in the interview, however, the teacher made reference to another strategy which brought the distinctive affordances of dragging the dynamic figure to bear on this issue:

When I talked about meeting at a point, they were able to move it around, and I think there's more potential to do that on the screen.

Likewise, his extended curriculum script depended on exploiting the distinctive affordance of the dynamic tool to explore how dragging the triangle affected the position of the 'centre'.

This suggests that the teacher's curriculum script was evolving through experience of teaching the lesson with dynamic geometry, incorporating 
new mathematical knowledge specifically linked to mediation by the software. Indeed, he drew attention to a striking example of this which had arisen from his question to the class about the position of the 'centre' when the triangle was dragged to become right angled. The lesson transcript recorded:

Teacher: What's happening to the [centre] point as I drag towards 90 degrees? What do you think is going to happen to the point when it's at 90 ?...

Student: The centre's going to be on the same point as the midpoint of the line.

Teacher [with surprise]: Does it always have to be at the midpoint?

[Dragging the figure] Yes, it is! Look at that! It's always going to be on the midpoint of that side.... Brilliant!

Reviewing the lesson, the teacher commented on this episode, linking it to distinctive features of the mediation of the task by the dynamic figure:

It was nice, because I don't know why it hadn't occurred to me, but it wasn't something I'd focused on in terms of the learning idea, but the point would actually be on the mid point. Of course it is. As soon as I'd said it I thought: "Of course!" But you know, in maths there's things that you just don't really notice because you're not focusing on them. And... I was just expecting them to say it was on the line. Because when you've got a compass point, you don't actually see the point, it's just a little hole in the paper, isn't it? But because the point is actually there and quite clear, a big red blob, then I saw it was exactly on that centre point, and that was good when they came up with that. I said: "Oh, is it?" Then I thought, I moved it and thought: "Don't be stupid, of course it is!" [Laughs]

In effect, his available curriculum script did not attune the teacher to this property. One can reasonably hazard that this changed as a direct result of this episode.

\section{Time economy}

In respect of the time economy, a very basic consideration of physical time for the teacher in this study was related to the proximity of the new computer suite to his normal classroom:

I'm particularly lucky being next door... If I was upstairs or something like that, it would be much harder; it would take five minutes to move down.

However, a more fundamental feature of this case was the degree to which the teacher measured didactic time in terms of progression towards securing student learning rather than pace in covering a curriculum. At the end of the first session, he linked his management of time to what he considered to be key processes at each stage of the investigation:

It's really important that we do have that discussion next lesson. Because they've seen it. Whether they've learned it yet, I don't know... They're probably vaguely aware of different properties and they've explored it, so it now needs to be brought out through a discussion, and then they can go and focus on writing things for themselves. So the process of exploring something, then discussing it in a quite focused way, as a group, and then writing it up... They've got to actually write down what they think they've learned. Because at the moment, I suspect... they've got vague notions of what they've learned but nothing concrete in their heads.

A further crucial consideration within the time economy is instrumental investment. The larger study from which this case derives showed that teachers were willing to invest time in developing students' instrumental knowledge of dynamic geometry to the extent that they saw this as promoting students' mathematical learning (Ruthven et al., 2008). As already noted, this teacher saw working with the software as engaging students in disciplined interaction with a geometric system. Consequently, he was willing to spend time to make them aware of the construction process underlying the dynamic figures used in lessons:

I very rarely use Geometer's Sketchpad from anything other than a blank page. Even when I'm doing something in demonstration... I always like to start with a blank page and actually put it together in front of the students so they can see where it's coming from.

Equally, this perspective underpinned his willingness to invest time in familiarising students with the 
software, recognising that it was possible to capitalise on earlier investment in using classical tools:

So I suppose in that getting them used to the program beforehand, giving a lesson where the aim wasn't to do that particular maths, but just for them to get familiar with it, showing them it both in here and next door, it was very helpful. And also they're doing the constructions by hand first, to see, getting all the words, the key words, out of the way.

As this recognition of a productive interaction between learning to use old and new technologies indicates, this teacher took an integrative perspective on the 'double instrumentation' entailed. Indeed, this was demonstrated earlier in his concern with the complementarity of old and new as components of a coherent resource system.

\section{Concluding thoughts}

We live at a time when there is an ever richer diversity of materials and tools available for school use. However, the main issue for curriculum developer and classroom teacher alike remains one of developing coherent use of a relatively small selection of them to form an effective resource system. As has been argued, this depends on coordinating resource system with working environment, activity format and curriculum script to underpin classroom practice which is viable within the time economy. This central challenge has tended to be overlooked in discussions of technology integration. It involves moving from idealised aspiration to effective realisation through the development of practical theory and craft knowledge.

Although only employing a dataset conveniently available from earlier research, the case analysis which has been presented illuminates the professional adaptation on which technology integration into classroom practice depends. This points to the value of conducting further studies in which data collection (as well as analysis) is guided by the conceptual framework developed in this paper. That is not to suggest that it should displace other conceptual frameworks, such as those drawn on by Artigue (2002, 2007) and by Monaghan (2004). Rather, the virtue of this framework is in providing a system of constructs closer to the 'lived world' of teacher experience and classroom practice. In this respect, it may prove able to fulfil an important mediating function, helping to translate insights from more decontextualised theories into practical ideas and action, and serving to draw attention to practical issues which have been overlooked or neglected in such theories.

Finally, the argument developed in this paper suggests that research on technology integration can benefit from taking a broad view which recognises that many of the same challenges confront other innovations, and are, indeed, already encountered in existing practice. In particular, there is scope for greater interaction to mutual advantage between what still remain largely separate traditions of research on educational technologies, curriculum materials, and teaching practices. 


\section{NOTES}

1. This paper is a revised and extended version of a plenary lecture (Ruthven, 2007) to CERME-5, the ${ }^{5 \text { th }}$ Congress of the European Society for Research in Mathematics Education.

2. A subsequent analysis covering mathematics, science and English teaching identified important commonalities across the three subjects, but also highlighted differences related to distinctive features of their subject cultures (Ruthven et al., 2004).

3. Thus 'resource' is used here to refer to some (physical or virtual) artefact which has either been designed specifically for curricular purposes, or been the subject of educational appropriation for such purposes: this usage is narrower (and more concrete, following the everyday language of teachers) than that of some authors (Adler, 2000; Gueudet \& Trouche, in press), but broader than that of curriculum material alone.

4. This concept of 'curriculum script' is related to what Gueudet $\&$ Trouche (in press) describe as a 'documentary system', specifically to the aspect concerned with cognitive organisation which shares a grounding in the cognitive science of practical competence.

5. 'Perpendicular bisector' in English corresponds to 'médiatrice' in French. The point at which the perpendicular bisectors of the sides of a triangle meet is the 'circumcentre' in English, the 'centre du cercle circonscrit' in French. However, in the course of the interview, the teacher referred to this centre as the 'orthocentre' rather than the 'circumcentre'. Note that it is now many years since reference to these (and other) terms - which distinguish the different 'centres' of a triangle - was removed from the school mathematics curriculum in England.

\section{ACKNOWLEDGEMENTS}

Particular thanks are due to the teacher colleague featured in the case study; to Rosemary Deaney who carried out the fieldwork for it; and to the UK Economic and Social Research Council which funded the associated research project. I am grateful also to the E \& D reviewers for their helpful suggestions.

\section{REFERENCES}

Abboud-Blanchard, M., Cazes, C., \& Vandebrouck, F. (2007). Teachers' activity in exercises-based lessons. Some case studies. In D. Pitta-Pantazi \& G. Philippou (Eds.), Proceedings of the Fifth Congress of the European Society for Research in Mathematics Education (pp. 1826-1836). Larnaca: CERME-5.

Adler, J. (2000). Conceptualising resources as a theme for teacher education. Journal of Mathematics Teacher Education, 3(3), 205-224.

Amarel, M. (1983). Classrooms and computers as instructional settings. Theory into Practice, 22, 260-266.

Artigue, M. (2002). Learning mathematics in a CAS environment: The genesis of a reflection about instrumentation and the dialectics between technical and conceptual work. International Journal of Computers for Mathematical Learning, 7(3), 245-274.

Artigue, M. (2007). Digital technologies: a window on theoretical issues in mathematics education. In D. Pitta-Pantazi \& G. Philippou (Eds.), Proceedings of the Fifth Congress of the European Society for Research in Mathematics Education (pp. 68-82). Larnaca: CERME-5.

Assude. T. (2005). Time management in the work economy of a class. A case study: Integration of Cabri in primary school mathematics teaching. Educational Studies in Mathematics, 59(2), 183-203. 
Ball, D. L., \& Cohen, D. K. (1996). Reform by the book: What is -or might be- the role of curriculum materials in teacher learning and instructional reform. Educational Researcher, 25(9), 6-8 \& 14.

Bauer, J., \& Kenton, J. (2005). Towards technology integration in schools: Why it isn't happening. Journal of Technology and Teacher Education, 13(4), 519-546.

Brown, S., \& McIntyre, D. (1993). Making Sense of Teaching. Buckingham: Open University Press.

Bueno-Ravel, L., \& Gueudet, G. (2007). Online resources in mathematics: Teachers' genesis of use. In D. Pitta-Pantazi \& G. Philippou (Eds.), Proceedings of the Fifth Congress of the European Society for Research in Mathematics Education (pp. 1369-1378). Larnaca: CERME-5.

Burns, R. B., \& Anderson, L. W. (1987). The activity structure of lesson segments. Curriculum Inquiry, 17(1), 31-53.

Burns, R. B., \& Lash, A. A. (1986). A comparison of activity structures during basic skills and problem-solving instruction in seventh-grade mathematics. American Educational Research Journal, 23(3), 393-414.

Caliskan-Dedeoglu, N. (2006). Usages de la géométrie dynamique par des enseignants de collège. Des potentialités à la mise en oeuvre: quelles motivations, quelles pratiques. Doctoral dissertation, University of Paris 7.

Conlon, T., \& Simpson, M. (2003). Silicon Valley versus Silicon Glen: the impact of computers upon teaching and learning: a comparative study. British Journal of Educational Technology, 34(2), 137-150.

Crisan, C., Lerman, S., \& Winbourne, P. (2007). Mathematics and ICT: a framework for conceptualising secondary school teachers' classroom practices. Technology, Pedagogy and Education, 16(2), 21-39.

Cuban, L. (1986). Teachers and Machines: The Classroom Use of Technology Since 1920. New York: Teachers College Press.

Cuban, L. (1993). Computer meets classroom: Classroom wins. Teachers College Record, 95(2), 185-210.

Cuban, L., Kirkpatrick, H., \& Peck, C. (2001). High access and low use of technologies in high school classrooms: Explaining an apparent paradox. American Educational Research Journal, 38(4), 813-834.

Deaney, R., Ruthven, K., \& Hennessy, S. (2006). Teachers' developing 'practical theories' of the contribution of information and communication technologies to subject teaching and learning: An analysis of cases from English secondary schools. British Educational Research Journal, 32(3), 459-480.

Fey, J. (2006). Connecting technology and school mathematics: A review of The didactical challenge of symbolic calculators: turning a computational device into a mathematical instrument. Journal for Research in Mathematics Education, 36(4), 348-352.

Gueudet, G., \& Trouche, L. (in press). Towards new documentation systems for mathematics teachers? Educational Studies in Mathematics.

Hennessy, S., Deaney, R., \& Ruthven, K. (2005). Emerging teacher strategies for mediating technology-integrated instructional conversations: a socio-cultural perspective. The Curriculum Journal, 16(3), 265-292.

Hennessy, S., Ruthven, K., \& Brindley, S. (2005). Teacher perspectives on integrating ICT into subject teaching: Commitment, constraints, caution and change. Journal of Curriculum Studies, 37(2), 155-192.

Jenson, J., \& Rose, C B. (2006). Finding space for technology: Pedagogical observations on the organization of computers in school environments. Canadian Journal of Learning and Technology 32(1). Accessed at http:// www.cjlt.ca/content/vol32.1/jenson.html

Jewitt, C., Moss, G., \& Cardini, A. (2007). Pace, interactivity and multimodality in teachers' design of texts for interactive whiteboards in the secondary school classroom. Learning, Media and Technology, 32(3), 303-317.

Kennedy, M. M. (1999). Ed schools and the problem of knowledge. In J. Raths \& A. McAninch (Eds.), What counts as Knowledge in Teacher Education? (pp. 29-45). Stamford, CT: Ablex.

Kerr, S. (1991). Lever and fulcrum: Educational technology in teachers' thought and practice. Teachers College Record, 93(1), 114-136. 
Kroath, F. (1989). How do teachers change their practical theories? Cambridge Journal of Education, 19(1), 59-69.

Kynigos, C., Bardini, C., Barzel, B., \& Maschietto, M. (2007). Tools and technologies in mathematical didactics. In D. Pitta-Pantazi \& G. Philippou (Eds.), Proceedings of the Fifth Congress of the European Society for Research in Mathematics Education (pp. 1332-1338). Larnaca: CERME-5.

Lagrange, J.-B., \& Caliskan-Dedeoglu, N. (in press). Usages de la technologie dans des conditions ordinaires: Le cas de la géométrie dynamique au collège: Potentialités, attentes, pratiques. Recherches en Didactique des Mathématiques.

Leinhardt, G. (1988). Situated knowledge and expertise in teaching. In J. Calderhead (Ed.) Teachers' Professional Learning (pp. 146-168). London: Falmer.

Leinhardt, G., Putnam T., Stein, M.K., \& Baxter, J. (1991). Where Subject Knowledge Matters. Advances in Research in Teaching, 2, 87-113.

Leinhardt, G., Weidman, C., \& Hammond, K. M. (1987). Introduction and integration of classroom routines by expert teachers. Curriculum Inquiry, 17(2), 135-176.

Monaghan, J. (2004). Teachers' activities in technology-based mathematics lessons. International Journal of Computers for Mathematical Learning, 9(3), 327-357.

Morgan, C. (1990). Carry on SMILEing. Micromath, 6(3), 14-15.

Miller, D., \& Glover, D. (2006). Interactive whiteboard evaluation for the Secondary National Strategy: Developing the use of interactive whiteboards in mathematics: Final report. Keele: Keele University.

Mullis, I., Martin, M., Gonzalez, E., \& Chrostowski, S. (2004). TIMMS 2003 International Mathematics Report. Boston: TIMSS \& PIRLS International Study Center, Boston College.

Munby, H., Russell, T., \& Martin, A. K. (2001) Teachers' knowledge and how it develops. In V. Richardson (Ed.), Handbook of Research on Teaching, Fourth Edition (pp. 877-904). New York: Macmillan.

Papert, S. (1997). Why school reform is impossible. The Journal of the Learning Sciences, 6(4), 417-427.

Remillard, J. (2005). Examining key concepts in research on teachers' use of mathematics curricula. Review of Educational Research, 75(2), 211-246.

Ruthven, K. (2002a). Linking researching with teaching: towards synergy of scholarly and craft knowledge. In L. English (Ed.), Handbook of International Research in Mathematics Education (pp. 581-598). Mahwah NJ: Lawrence Erlbaum.

Ruthven, K. (2002b). Instrumenting mathematical activity: Reflections on key studies of the educational use of computer algebra systems. International Journal of Computers for Mathematical Learning, 7(3), 275-291.

Ruthven, K. (2007). Teachers, technologies and the structures of schooling. In D. Pitta-Pantazi \& G. Philippou (Eds.), Proceedings of the Fifth Congress of the European Society for Research in Mathematics Education (pp. 52-67). Larnaca: CERME-5.

Ruthven, K. (in press). The didactical challenge of technology integration in school mathematics. In D. Moreira (Ed.), Proceedings of the 17 $7^{\text {th }}$ Annual Meeting of the Mathematics Education Section of the Portuguese Society for Educational Sciences.

Ruthven, K., \& Hennessy, S. (2002). A practitioner model of the use of computer-based tools and resources to support mathematics teaching and learning. Educational Studies in Mathematics, 49(1), 47-88.

Ruthven, K., Hennessy, S., \& Brindley, S. (2004). Teacher representations of the successful use of computerbased tools and resources in secondary-school English, Mathematics and Science. Teaching and Teacher Education, 20(3), 259-275.

Ruthven, K., Hennessy, S., \& Deaney, R. (2005a). Incorporating dynamic geometry systems into secondary mathematics education: Didactical perspectives and practices of teachers. In D. Wright (Ed.), Moving on with Dynamic Geometry (pp. 138-158). Derby: Association of Teachers of Mathematics. 
Ruthven, K., Hennessy, S., \& Deaney, R. (2005b). Incorporating Internet resources into classroom practice: Pedagogical perspectives and strategies of secondary-school subject teachers. Computers and Education, 44(1), 1-34.

Ruthven, K., Hennessy, S., \& Deaney, R. (2008). Constructions of dynamic geometry: a study of the interpretative flexibility of educational software in classroom practice. Computers and Education, 51(1), 297-317.

Smerdon, B., Cronen, S., Lanahan, L., Anderson, J., Iannotti, N., Angeles, J., \& Greene, B. (2000). Teachers' tools for the $21^{\text {st }}$ century: A report on teachers' use of technology. Washington DC: US Department of Education, National Center for Education Statistics.

Spillane, J. P., Reiser, B. J., \& Reimer, T. (2002). Policy implementation and cognition: Reframing and refocusing implementation research. Review of Educational Research, 72(3), 387-431.

Trouche, L. (2005). Instrumental genesis, individual and social aspects. In D. Guin, K. Ruthven, \& L. Trouche (Eds.), The didactical challenge of symbolic calculators: turning a computational device into a mathematical instrument (pp. 197-230). New York: Springer.

Tyack, D., \& Tobin, W. (1994). The "grammar" of schooling: Why has it been so hard to change? American Educational Research Journal, 31(3), 453-479.

Warschauer, M., \& Grimes, D. (2005). First year evaluation report: Fullerton School District Laptop Program. Irvine CA: University of California, Irvine.

Wood, D. (1998). The UK ILS evaluations: Final report. Coventry: BECTA.

Yackel, E., \& Cobb, P. (1996). Sociomathematical norms, argumentation, and autonomy in mathematics. Journal for Research in Mathematics Education, 27(4), 458-477.

Zucker, A., \& McGhee, R. (2005). A study of one-to-one computer use in mathematics and science instruction at the secondary Level in Henrico County public schools. Menlo Park CA: SRI International. 